Original Article

\title{
ANTIBIOTIC SENSITIVITY PATTERN OF BACTERIA ISOLATED FROM THE ENVIRONMENT OF INTENSIVE CARE UNIT OF WAD MEDANI EMERGENCY HOSPITAL, GEZIRA STATE, SUDAN
}

\author{
WALEED ELSIDDIG MOHAMMED ${ }^{1}$, HASSABELRASOUL ELFADIL HASSAN ${ }^{2 *}$, MIRGHANI ABDELRHMAN YOUSIF ${ }^{*}$
}

1National Health Insurance Fund, Gezira State, Sudan, 2Department of Natural Product and Alternative Medicine, Faculty of Pharmacy, University of Tabuk, Tabuk, Kingdom of Saudi Arabia, ${ }^{3}$ Department of Pharmacy Practice, Faculty of Pharmacy, University of Gezira, Sudan Email: helfadil65@gmail.com

Received: 13 Jun 2020, Revised and Accepted: 16 Aug 2020

\begin{abstract}
Objective: The objective of the present study was primarily to identify the sources and types of bacterial contamination associated with hospitalacquired infections in the intensive care unit and to investigate the sensitivity pattern of isolated bacteria to prescribed antibiotics of Wad Medani Emergency Hospital, Gezira State, Sudan.

Methods: A total of 50 swab samples were obtained from 14 different sites, including inanimate objects as well as nurses' hands in the ICU. Identification of the bacterial isolates was performed utilizing Gram's staining test and standard biochemical tests; likewise, the respective antimicrobial sensitivity was determined based on the guidelines recommended by the Clinical and Laboratory Standards Institute (CLSI).

Results: Showed the prevalence of Gram-positive isolates as Coagulase-negative staphylococci (30\%), Staphylococcus aureus (20\%), Bacillus spp (15\%), and Streptococcus spp (4\%). On the other hand, the Gram negative isolates were: Pseudomonas aeruginosa (11\%), IKliebsiella pneumoniae (7\%), Proteus mirabilis (5\%), and Enterobacter spp.(5\%). Floor, Monitors, Patients' oxygen masks and infusion-stands as well as nurses' hands, were the most contaminated sites. Staphylococci showed a reasonable sensitivity response to Gentamicin and Vancomycin and high resistance to Erythromycin and Co-trimoxazole; whereas Gram-negative isolates showed high resistance to first and second-generation Cephalosporins and demonstrated good sensitivity pattern to Gentamicin and Meropenem. Pseudomonas aeruginosa also showed reasonable sensitivity to Ciprofloxacin.
\end{abstract}

Conclusion: Findings of the study demonstrated high bacterial contamination levels in ICU.

Keywords: Hospital acquired infections, Intensive Care Unit, Contamination, Environment

(C) 2020 The Authors. Published by Innovare Academic Sciences Pvt Ltd. This is an open access article under the CC BY license (http://creativecommons.org/licenses/by/4.0/) DOI: http://dx.doi.org/10.22159/ijcpr.2020v12i5.39772. Journal homepage: https://innovareacademics.in/journals/index.php/ijcpr

\section{INTRODUCTION}

Hospital-acquired infections (HAIs), known as nosocomial infections, are infections occurring in a patient in a hospital or other healthcare facility in whom the infection was not present or incubating at the time of admission. This includes infections acquired in the hospital but appearing after discharge, and also occupational infections among staff of the facility $[1,2]$. Nosocomial infections represent one of the major causes of preventable injuries and deaths in hospitals, affecting $5 \%$ to $10 \%$ of hospitalized patients [3]. HAIs occurred in every healthcare facility and affecting hundreds of millions of patients every year worldwide and resulted in increased morbidity and mortality. Nosocomial infections generate additional cost to those already incurred by the patient's underlying disease due to prolonged duration of hospital stays and additional diagnostic and therapeutic interventions [4]. Also hospital-acquired infections trigger another problems that reduce quality of life such as functional disabilities and emotional stress of the patients [5]. Prevalence of HAIs was about $18 \%$ and the prevalence is highest in the intensive care unit (50\%) in Morocco [6]. Given the critical conditions and exposure to medical devices, the risk for infection is greater in ICU and increased with duration of stay. Patients in ICU were also exposed to non-critical devices, i.e. objects that come in contact with intact skin; these include blood pressure cuff, stethoscope, pulse Oximetry sensor, ultrasound transducers and electrocardiography leads. Intact skin acts as an effective barrier to most microorganisms; therefore, these items have been said to pose virtually no risk for transmission of infectious agents. However, numerous studies have shown that non-critical devices could be contaminated with pathogens, including those resistant to antibiotics and therefore become a potential source of hospital-acquired infections HAIs [4]. The emergence of multidrugresistant bacteria (MDRB) has become a public health problem, creating a new burden on medical care in hospitals, particularly for patients admitted to intensive care units (ICU). In critical care units, there is extensive antimicrobial use, which imposes a selection pressure and promotes the emergence of MDRB. In addition to this, ICU patients had an increased risk of infection due to their underlying diseases or conditions, impaired immunity, and exposure to multiple invasive devices (mechanical ventilation, central venous catheters (CVC), and urinary tract catheters [7].

Inanimate surfaces near infected patients and those frequently touched surfaces within the hospital environment are reservoirs of Pseudomonas aeruginosa, Escherichia coli and Staphylococcus aureus. The hands of healthcare workers can readily acquire pathogens after contact with contaminated hospital surfaces or patients and can transfer these pathogens to subsequently touched patients and inanimate surfaces [8]. Most nosocomial pathogens can persist on inanimate surfaces for weeks or even months [9]. The microorganisms that cause nosocomial infections are acquired from health care environment. The hospital exists as a closed community so that it is possible microorganism disseminate and cause diseases. The pathogen can be transmitted directly from patient to patient or indirectly from the environmental surfaces $[8,10]$.

The most-reported bacteria that cause nosocomial infections include Staphylococcus aureus, Streptococcus spp., Bacillus cereus, Acinetobacter spp., Coagulase-negative staphylococci, enterococci, Pseudomonas aeruginosa, Legionella and members of the Enterobacteriaceae family such as Escherichia coli, Proteus mirabilis, Salmonella spp., Serratia marcescens and Kliebsiella pneumonia [1].

\section{MATERIALS AND METHODS}

Description of the study

The study was a prospective, cross-sectional, one center microbiological study, conducted in the intensive care unit of Wad Medani Emergency Hospital. 


\section{Collection and transport of the swab samples}

Fifty samples were collected from inanimate objects, and from nurses' hands; from 12-bed intensive care unit (ICU). The samples were randomly collected from the following inanimate objects; Beds, Chairs, Patient Tables, Doctors tables, Monitors, ECG, Ventilators, Nebulizer, Masks of Oxygen suppliers, Drip stands, Floor, walls, water sink and from nurses hands. The samples were collected with sterile cotton swabs. The cotton swabs were moistened with sterile normal saline before sampling of the objects, and the sampled swabs were placed into sterile transport containers. Moistened swab samples from surfaces of inanimate objects and nurses hand were taken, then as soon as possible, samples were taken to the microbiology laboratory of the Faculty of Pharmacy, University of Gezira,(About five hundred meters far from the hospital), for culture, Gram Stain biochemical tests, and sensitivity testing. The sampled swabs were immediately inoculated into prepared medium [11-13].

\section{Isolation of bacteria}

All samples were inoculated on MacConkey, Nutrient agar and Blood agar, incubated at $37 \circ \mathrm{C}$ for overnight, and colonies were subcultured. Subculture was made for all mixed bacterial growth to yield pure isolates of bacteria. Then morphological, blood hemolytic activity, microscopical and biochemical characteristics had been studied according to the procedure described by Nasser et al., (2013) [14]. The purified colonies were subsequently preserved in Nutrient agar slants for further use [15].

\section{Laboratory examination of cultures}

\section{Morphological and macroscopical examination}

Presumptive identification was made for bacterial colonies according to their characteristic appearance on their respective media [16].

\section{Biochemical testing}

The following biochemical tests were employed for this study: Catalase to differentiate streptococci from staphylococci, Coagulase and mannitol tests for differentiation of Staphylococcus spp; citrate, oxidase, indole, urease, and lactose fermentation tests for identification of Pseudomonas aeruginosa, and Enterobacteriaceae [17].

\section{Sensitivity testing}

The isolates were tested for their susceptibility to 12 different antimicrobials drugs (Himedia, India) using the Kirby-bauer disk diffusion method: Oxacillin $(1 \mu \mathrm{g})$, Vancomycin $(30 \mu \mathrm{g})$, Ciprofloxacin $(5 \mu \mathrm{g})$, Erythromycin $(15 \mu \mathrm{g})$, Co-trimoxazole $(25 \mu \mathrm{g})$, Gentamicin $(30 \mu \mathrm{g})$, Cephazoline $(30 \mu \mathrm{g})$, Ceftazidime $(30 \mu \mathrm{g})$, Cefuroxime $(30 \mu \mathrm{g})$, Meropenem $(10 \mu \mathrm{g})$, Ceftriaxone $(30 \mu \mathrm{g})$ and Ceftizoxime $(30 \mu \mathrm{g})$ were used. By the standard method of inoculation, a loopful culture of isolates was inoculated into 3 to $4 \mathrm{ml}$ Nutrient broth. The concentration of the broth cultures was then adjusted to a 0.5 McFarland standard. A sterile cotton swab was dipped into broth suspension and excess broth purged by pressing and rotating the swab firmly against the inside of the tube. The swab was then spread evenly over the entire surface of the plate agars to obtain uniform inoculums. Plates were then allowed to dry for 3 to $5 \mathrm{~min}$. The antibiotic disks were gently applied to ensure their contact with the inoculated Mueller-Hinton agar surface and incubated at $37^{\circ} \mathrm{C}$. The plates were observed after 18-24 $\mathrm{h}$ and the zones of inhibition were measured by a ruler. The zone diameter for individual antimicrobial agents was interpreted using the Clinical and Laboratory Standards Institute (CLSI-2014) Formerly known as National Committee of Clinical Laboratory Standards (NCCLS).

\section{RESULTS AND DISCUSSION}

\section{Distribution of isolated bacteria}

Number of Gram-positive isolates was higher than Gram-negative isolates in 50 analyzed swab samples. Out of 85 isolates identified, 58 constituting (68.2\%) were Gram-positive, the remaining were Gram-negative. Of the Staphylococci isolated the S. epidermidis was representing about (24\%) of the total population of isolates followed by $S$. aureus representing (20\%). The Bacillus spp was 13 (15\%). These results were consistent with findings made by Ekrami et al. (2011) [18]. The prevalence of Staphylococcus saprophyticus and streptococcus spp was $(6 \%)$ and $(4 \%)$ respectively. These results coincide with findings made by Shiferaw et al. (2013) [19].

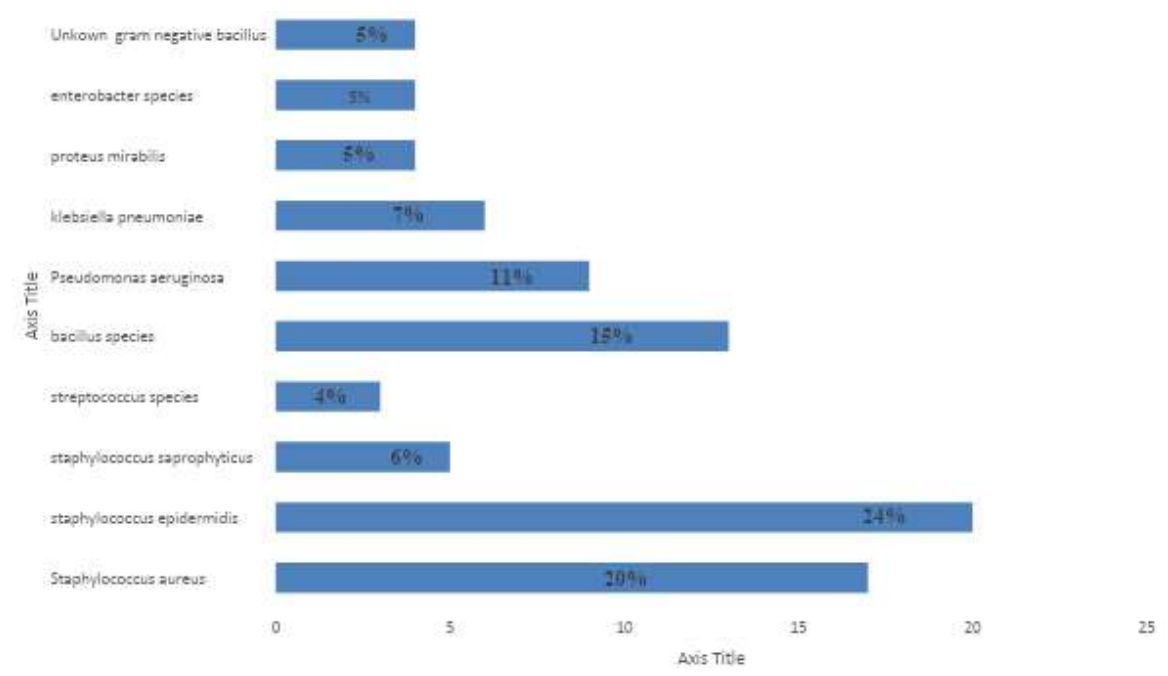

Fig. 1: Distribution of isolated bacteria in study sample

Among Gram-negative Pseudomonas aeruginosa isolates were the most prevalent organism, which was (11\%) followed by Klebsiella pneumoniae, which was $(7 \%)$ and least prevalent organisms were Proteus mirabilis and Enterobacter species with a prevalence of (5\%) for each (fig. 1). S. epidermidis was the most frequently isolated from all the samples collected from the ICU. This was followed closely by S. aureus; these results were in agreement with Chikere et al., (2008) [1]. The latter reported results of $39 \%$ and $28 \%$, respectively. The reason for this may be explained by the fact that staphylococci are major part of the body flora of both asymptomatic carriers in addition to infected persons. These organisms can be spread by hands of patients, expelled from the respiratory tract or transmitted by animate or inanimate objects [1]. Coagulase-negative staphylococci were found to be the major causative agent of bloodstream infections. This observation was consistent with the work made by Abubakar et al., $[20,21]$ and the (BSI) Most CoNS-associated neonatal infections were caused by S. epidermidis [22]. Staphylococcus aureus represents global problem in the medical field due to their possession of antibiotic- 
resistant genes. There are numerous reported cases of emerging nosocomial infections caused by methicillin resistant S. aureus (MRSA), vancomycin-resistant S. aureus (VRSA) and other multi-drug (MDR) resistant strains $[20,23,24]$.

Among Gram-negative isolates Pseudomonas aeruginosa was the most common organism when compared with Klebsiella pneumoniae, Proteus mirabilis and Enterobacter species. This finding was actually in accordance with the works of Lestari,T. S. et al., Hammuel, C., E. D et al., Yahya, F., et al., [4, 8, 25]. Pseudomonas aeruginosa is an important cause of nosocomial infections, especially in the intensive care unit and neutropenic patients. Also, it is a multidrug resistant pathogen [26]

\section{Distribution of pure isolates on the sites}

Environmental contamination may contribute to the transmission of nosocomial pathogens when healthcare providers contaminate their hands or gloves by touching contaminated surfaces, or when patients come into direct contact with contaminated surfaces [27, 28]. Equipment and materials in use in hospitals often become contaminated with microorganisms, which may subsequently transferred to susceptible body sites of patients [29]. In the present study the most contaminated surfaces were floor and monitors being 11isolates/5samples for each. These findings agreed with results obtained by Nasser et al., (2013) [14] in study conducted in Iraq. This is maybe due to inadequate disinfection and absence of standard procedure for decontamination of medical equipment. On the other hand two of most frequently touched objects (Masks of oxygen supply and Drip stands) were highly contaminated, particularly by CoNS which may be transferred from nurses' hands. Tables of patients, Beds, chairs and tables of nurses were also contaminated with Staphylococcus spp. Ventilators, Nebulizer and ECG were the least contaminated objects (table 1). Pseudomonas aeruginosa isolates were found in Floor, Beds and Drip stands.

Table 1: Distribution of pure isolates on the sites and types of Bacteria

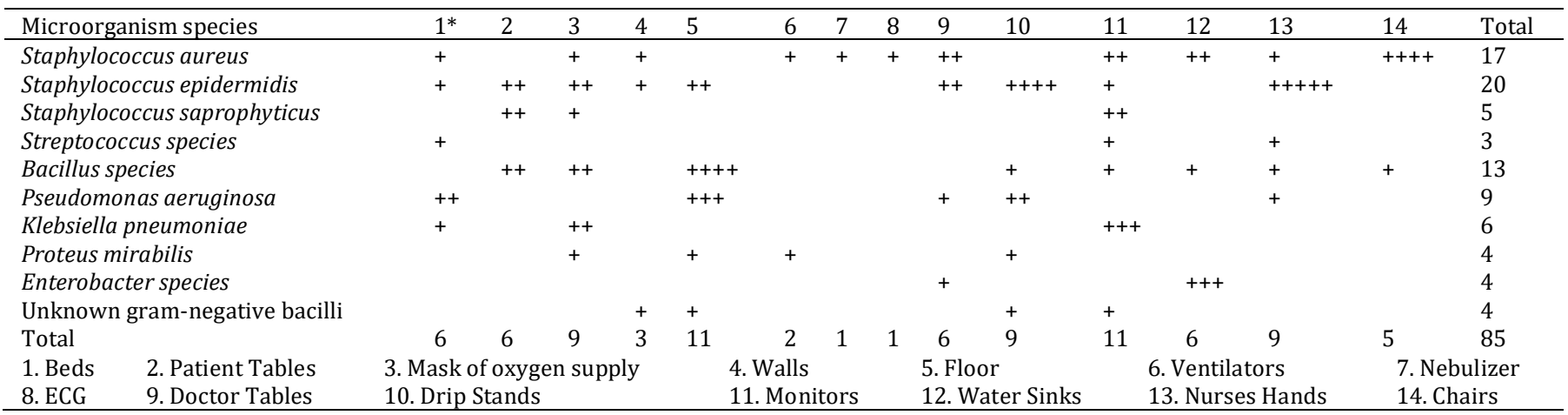

Sensitivity of bacterial isolates towards antimicrobials

Table 2: Antibiotic resistance pattern of isolated bacteria

\begin{tabular}{|c|c|c|c|c|c|}
\hline Antimicrobial agent $(\mu \mathrm{g})$ & Staph spp. $\mathrm{N}=42$ & Entero $\mathrm{N}=14$ & P. aeruginosa $\mathrm{N}=9$ & Bacillus $\mathrm{N}=13$ & Strep N=3 \\
\hline Gentamicin & $4(10 \%)$ & NR & $\mathrm{NR}$ & NR & $2(67 \%)$ \\
\hline Meropenem & NT & $1(7 \%)$ & NR & NR & NT \\
\hline Vancomycin & $9(21 \%)$ & NT & NT & $\mathrm{NR}$ & NR \\
\hline Ciprofloxacin & $21(50 \%)$ & NT & NR & $3(23 \%)$ & NR \\
\hline Oxacillin & $15(36)$ & NT & NT & $5(39 \%)$ & $\mathrm{NT}$ \\
\hline Ceftriaxone & NT & $5(36 \%)$ & $3(33 \%)$ & $\mathrm{TN}$ & $2(67 \%)$ \\
\hline Ceftizoxime & NT & NT & $5(56 \%)$ & NT & $2(67 \%)$ \\
\hline Erythromycin & $28(67 \%)$ & NT & NT & $1(8 \%)$ & $3(100 \%)$ \\
\hline Ceftazidime & NT & $12(86 \%)$ & $6(67 \%)$ & NT & NT \\
\hline Co-trimoxazole & $33(79 \%)$ & NT & NT & NT & $2(67 \%)$ \\
\hline Cefuroxime & NT & $13(93 \%)$ & NT & NT & $\mathrm{NT}$ \\
\hline Cephazoline & NT & $14(100 \%)$ & NT & NT & NT \\
\hline
\end{tabular}

$\mathrm{NT}=$ Not tested, NR= No resistance, Staph spp. = Staphylococcus spp., Entero = Enterobacteriaceae, $\mathrm{P}=$ Pseudomonas, Strep= Streptococcus spp .

Sensitivity tests for some antibiotics showed different results depending on the genus of bacteria and type of antibiotic. Staphylococcus spp isolates showed high resistance to Co-trimoxazole (79\%), Erythromycin (67\%), and Ciprofloxacin (50\%). These findings agreed with Abu-Bakr et al., (2014) [30]. The relatively low resistance of Staphylococcus spp. to Vancomycin in agreement with Hummel et a., (2014) [31-33] in Nigeria. The members of Enterobacteriaceae isolates showed $(100 \%)$ resistance to Cephazoline and (93\%), (86\%) for Cefuroxime and Ceftazidime, respectively. The latter two agents are the most frequently prescribed antimicrobials in the ICU of Wad Medani Emergency Hospital. Gentamicin and Meropenem were the most effective drugs against isolated enterobacteria. One of the most disappointing findings of this study was the presence of highly resistant isolates of Pseudomonas aeruginosa to Ceftriaxone, Ceftizoxime and Ceftazidime because these are the most frequently prescribed antibiotics in the Wad Medani hospital. Pseudomonas aeruginosa showed high sensitivity to Ciprofloxacin; this result was complying with medical literature which revealed that, fluoroquinolones exhibit good activity against Pseudomonas aeruginosa but resistance to these agents may develop, this was consistent with the study of Ekrami et al.,(2011) [18] who showed that Pseudomonas aeruginosa (79\%) sensitive to Gentamicin. Treatment of $P$. aeruginosa infections remains challenging.

\section{CONCLUSION}

This study which was conducted in one of the major teaching hospital settings in Gezira state central Sudan, through sampling of ICU equipment and personnel. Findings managed to explore a number of limitations, which need to be considered. The contamination levels in the intensive care unit of Wad Medani Emergency hospital were found to be extraordinarily high particularly for the ICU equipment; the factor which raises multiple questions and rings the alarming bell to the threat facing patients and personnel attending the department. 


\section{ACKNOWLEDGMENT}

This work was partially supported by the National Health Insurance fund, Gezira state.

\section{AUTHORS CONTRIBUTIONS}

All the authors have contributed equally.

\section{FUNDING}

Nil

\section{CONFLICT OF INTERESTS}

Authors declared that no conflict of interest.

\section{REFERENCES}

1. Chikere C, V Omoni, B Chikere. Distribution of potential nosocomial pathogens in a hospital environment. Afr J Biotechnol 2008;7:3535-9.

2. Ducel G, J Fabry, L Nicolle. Prevention of hospital-acquired infections: a practical guide. World Health Organization; 2002.

3. Berriel Cass D. Eliminating nosocomial infections at Ascension Health. Joint Commission J Quality Patient Safety 2006;32:612-20.

4. Lestari T, S Ryll, A Kramer. Microbial contamination of manually reprocessed, ready to use ECG lead wire in intensive care units. GMS Hygiene Infection Control 2013;8:1-7.

5. Ducel G, J Fabry, LE Nicolle. Prevention of hospital-acquired infections: a practical guide. 2nd edition. World Health Organization; 2002.

6. Jroundi I. Prevalence of hospital-acquired infection in a moroccan university hospital. Am J Infection Control 2007;35:412-6.

7. Cornejo Juarez P. The impact of hospital-acquired infections with multidrug-resistant bacteria in an oncology intensive care unit. Int J Infectious Diseases, 2015;31:31-4.

8. Hammuel C, ED Jatau, CMZ Whong. Prevalence and antibiogram pattern of some nosocomial pathogens isolated from the hospital environment in zaria, Nigeria. Aceh Int J Sci Technol 2014;3:131-9.

9. Kramer A, I Schwebke, G Kampf. How long do nosocomial pathogens persist on inanimate surfaces? A systematic review. BMC Infectious Diseases 2006;6:130-7.

10. Dancer S. How do we assess hospital cleaning? A proposal for microbiological standards for surface hygiene in hospitals. J Hospital Infection 2004;56:10-5.

11. Teng SO. Bacterial contamination of patients' medical charts in a surgical ward and the intensive care unit: impact on nosocomial infections. J Microbiol Immunol Infect 2009;42:86-91.

12. Keerasuntonpong A. Colonization of nosocomial pathogens on computer keyboards in patient care areas. Siriraj Med J 2005;57:380-1.

13. Whittington AM. Bacterial contamination of stethoscopes on the intensive care unit. Anaesthesia 2009;64:620-4.

14. Nasser NE, AT Abbas, SL Hamed. Bacterial contamination in intensive care unit at Al-Imam Al-hussein hospital in the thi-qar province in Iraq. Glob J Health Sci 2013;5:143-9.

15. Sharma D, PK Sharma, A Malik. Prevalence and antimicrobial susceptibility of drug-resistant staphylococcus aureus in raw milk of dairy cattle. Int Res J Microbiol 2011;2:466-70.

16. Elmanama AA, NEA Tayyem, SAN Allah. The bacterial etiology of otitis media and their antibiogram among children in gaza strip, palestine. Egyptian J Ear Nose Throat Allied Sci 2014;15:87-91.
17. Cheesbrough M. District laboratory practice in tropical countries. $2^{\text {nd }}$ ed. Vol. 2. london: Cambridge University Press; 2006. p. 434.

18. Ekrami A. Isolation of common aerobic bacterial pathogens from the environment of seven hospitals, Ahvaz, Iran. JJM 2011;4:75-82.

19. Shiferaw T. Bacterial contamination, bacterial profile and antimicrobial susceptibility pattern of isolates from stethoscopes at Jimma University Specialized Hospital. Annals Clin Microbiol Antimicrobials 2013;12:39-47.

20. Inweregbu K, J Dave, A Pittard. Nosocomial infections. Continuing Education in Anaesthesia, Critical Care and Pain 2005;5:14-7.

21. Abubakar AS. Spectrum of bacterial isolates among intensive care unit patients in a tertiary hospital in northern Nigeria. Ind J Sci Res Tech 2014;2:42-7.

22. Cimiotti JP. Prevalence and clinical relevance of staphylococcus warneri in the neonatal intensive care unit. Infection Control 2007;28:326-30.

23. Kheder SI, NA Ali, AI Fathelrahman. Prevalence and antimicrobial susceptibility pattern of methicillin resistance staphylococcus in a sudanese surgical ward. Pharmacol Pharm 2012;3:103-8.

24. Savaș L. Prevalence of methicillin-sensitive and methicillinresistant staphylococci in intensive care units in a University Hospital. Eur J Gen Med 2005;2:20-6.

25. Yahya F. Microbiological screening of the environments of two hospitals in Nablus. An-Najah J Res 1995;3:100-7.

26. Greenwood D. Medical microbiology: a guide to microbial infections: pathogenesis, immunity, laboratory diagnosis and control. With Student Consult 18 ${ }^{\text {th }}$ ed. Edinburgh: Churchill Livingstone Elsevier; 2012. p. 777.

27. Boyce JM. Environmental contamination makes an important contribution to hospital infection. J Hospital Infection 2007;65:50-4.

28. Damaceno QS, R Iquiapaza, AC Oliveira. Comparing resistant microorganisms isolated from patients and the environment in an intensive care unit. Adv Inf Diseases 2014;4:30-5.

29. Slack RC. Hospital infection, in medical microbiology: a guide to microbial infections: pathogenesis, immunity, laboratory diagnosis and control. With student consult. D Greenwood. Editors. Churchill Livingstone Elsevier: Edinburgh; 2012. p. 718-26.

30. Abubakar ASB, MM Balla, HJ Tanimu, YS Waru, GB Dibal J. Spectrum of bacterial isolates among intensive care unit patients in a tertiary hospital in northern Nigeria. Ind J Sci Res. Tech 2014;2:42-7.

31. Hammuel C, ED Jatau, CM Whong. Prevalence and antibiogram pattern of some nosocomial pathogens isolated from hospital environment in Zaria, Nigeria. Aceh Int J Sci Technol 2014;3:131-9.

32. Teshale Worku, Dejene Derseh, Abera Kumalo. Bacterial profile and antimicrobial susceptibility pattern of the isolates from stethoscope, thermometer, and inanimate surfaces of mizantepi university teaching hospital. Southwest Ethiopia Int J Microbiol 2018;2:1-7.

33. Sneha S Savanur, Hemamalini Gururaj. Indian study of antibiotic sensitivity and resistance pattern of bacterial isolates in intensive care unit setup of a tertiary care hospital. J Crit Care Med 2019;23:547-55. 